\title{
Comparison of Effective in Batik Production Process between Paraffin Wax and Gel Wax-Resist
}

\author{
Sarath Simsiri
}

\begin{abstract}
Comparison of effective in Batik production process between paraffin wax and gel wax-resist. This study focuses on the characteristics of Batik painting resist and to compare the Batik production processes between those wax-resist, to provide formal guidance how differences to make Batik both process. The research concluded that the Batik painting with gel wax can reduce the Batik equipment, less energy and time in overall process. The means of the opinion on production process and Batik identity from users using gel wax resist material were higher than the those of users using paraffin wax resist material with statistically significant $(\mathbf{p}<0.05)$.
\end{abstract}

Index Terms-Batik painting, batik resist, paraffin wax, gel wax.

\section{INTRODUCTION}

The method of Batik painting begins with using resist material on fabric before color painting. Traditional resist material was mud, wax or starch. In Thailand, most of the resist material made from bee wax mixes with plant resin or paraffin [1]. Many instruments and materials used in Batik painting including paraffin or wax pen, wire, paraffin wax boiling set, cloth, dye, brushes, wood frame, wood frame stand, coating solution, boiling set, and a pen-like instrument called Tjanting [2] that is an important instrument for Batik drawing. Tjanting made of copper or brass. It is used to carry paraffin wax to draw dots or lines on fabric according to the pattern. As [3] mentioned that drawing pattern on Batik cloth by using Tjanting was the best method for Batik drawing because it could generate small lines resulting in the very detailed pattern.

Batik or Pateh is one of the clothes made with a unique technique. It made by drawing on the fabric with paraffin wax to cover the area that does not want to dye incorporate with painting in the specific area [3]. There are many instruments for doing Batik depending on characteristics of Batik. Draw-type Batik needs to use Tjanting to draw patterns on fabric. Its handle made from wood. There is a reservoir on the top of Tjanting to hold the resist material (hot paraffin wax). Resist material passes through the small channel of the Tjanting and make lines or dots on the fabric. Due to a unique characteristic of Tjanting different from another pen, a new painter may be in trouble to draw a line with it. Additionally, Tjanting is likely to be stuffed with dust from paraffin wax. Hot paraffin wax also could not be drawn on thick fabric because the hot paraffin wax becomes cold

Manuscript received May 5, 2019; revised June 13, 2019.

S. S. Author is with the School of Tourism and Hospitality, Suan Dusit University, Bangkok, Thailand (e-mail: Sarath308@hotmail.com). and hard before get through the other side. Therefore, it could not be a good border of dyes. Regarding melting paraffin wax, heat is a need, and this causes smoke and disturbs the working area and may be harmful to the workers [1], [3]. The limitation of making Batik with Tjanting is the control the temperature of hot paraffin wax. A too high temperature of melt paraffin wax causes diffusion of the lines, and also the low temperature of warm paraffin wax causes paraffin wax does not get through the other side of the fabric. Moreover, melt paraffin wax may drop from the reservoir to the fabric and cause a defect. Therefore, a new Batik painter is not able to draw a good line and needs to practice on drawing with Tjanting because Tjanting is so different from a standard pen [4], [5].

Frequently, Batik painting needs three different sizes of Tjanting including small, medium and large. They require use resist material, which is the mixture of paraffin wax, plant resin, plant or animal fat. The crucial issue of resist material is melting into liquid wax. Therefore, it needs to use with other instruments including stove and pot for boiling. Previously, Batik painting was done by only using paraffin wax melted with heat. In Europe, recently a new resist material has been used. It is not paraffin wax but has paraffin wax characteristics without using heat. The new resist material is liquid and could be a border for dyes like paraffin wax [6]. This resist material does not need heat to melt and is used in some groups in Thailand to make Batik, but it is costly. However, new resist material has been developed to substitute traditionally natural resist material, such as rice, soy or konjac starch, but it could not draw a distinct line like paraffin wax, and it needs to wait for drying those materials. Therefore, the process of making Batik consumes more time. Moreover, this new resist material could not make the same quality of Batik. Efficacy comparison between paraffin wax and gel wax as the resist material in Batik painting begins with researcher discovers resist material, which does not need heat to melt. It is gel-like characteristic and could be used to draw line and pattern instead of former paraffin wax technique. The new liquid gel resist material is contained in a specific pen, there are 23 different sizes of the needle tip as appropriate in different pattern and also use instead of the original paraffin wax Batik painting without having to wait until dry. It also reduces the process, the materials and equipment for Batik painting. Anyone without Batik painting experience can write Batik pattern more easily. Including compare quality of traditional uniqueness of Batik cloth from traditional paraffin wax technique with new gel wax technique. As Srisawat [7] states: The invention of the new product must preserve the layout of the original art or culture. And also, this research has changed some Batik process and 
tools used in production. All the same the researcher still focus on the Batik characteristics that is inherited from the past lead to the basis for comparative study. In order to take that information into the benefits associated with effectiveness use in Batik painting.

This study thus focuses on the performance comparison between Paraffin Wax-Resist and Gel Wax-Resist including batik equipment, the process of work, fast process technology, cost and convenience. The objective of this paper is to investigate characteristics of gel wax resist material in Batik painting. To compare the Batik production processes by comparing the efficacy of batik painting made with paraffin wax technique and gel wax technique including compare traditional uniqueness of Batik cloth from paraffin wax technique and gel wax technique. The result may be use as a guideline to use and benefit the batik art in the future.

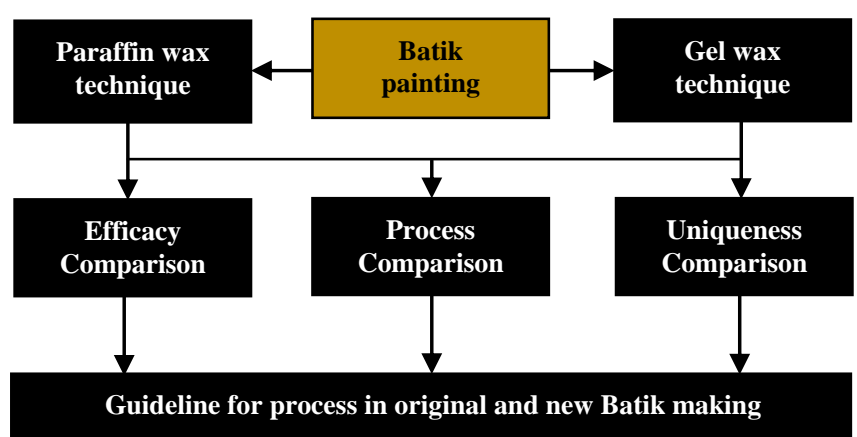

Fig. 1. Research Framework.

\section{The Purpose OF THE RESEARCH}

This study focuses on the performance comparison between Paraffin Wax-Resist and Gel Wax-Resist including batik equipment, the process of work, fast process technology, cost and convenience. The objective of this paper is to investigate characteristics of gel wax resist material in Batik painting. To compare the Batik production processes by comparing the efficacy of batik painting made with paraffin wax technique and gel wax technique including compare traditional uniqueness of Batik cloth from paraffin wax technique and gel wax technique.

\section{RESEARCH METHODOLOGY}

This research is qualitative research to investigate the facts under theory and framework of research. The target group specified with the systematically scientific method. Data was collected from the questionnaire and statistically analyzed to explain characteristics and correlations between factors according to objectives. Specific characteristics of gel wax resist material and paraffin wax resist material was investigated and compared in these following aspects such as, (1) efficacy of batik painting; Efficacy on being a good border for different dyes, Efficacy on being a border with constant thickness, Control direction of drawing, Change of size pen, Size of pen is suitable for each work, No strong odor, No needed heat, Resist material does not leak or drop from reservoir down to fabric, The Batik pen is strong, Easy to draw different patterns, Easy to refill resist material, Easy to remove from fabric, Easy to clean the tip of Tjanting and Tip of Tjanting is not clogged. (2) The characteristics of Batik cloth; Lines are distinct, Lines are fragile and detailed, Brightness of colors, Shades of colors, Neat of colors, Cleanliness of cloth, Neat of cloth and Uniqueness of Batik. And (3) Batik production processes in time and water used; Pen drawing, Equipment preparing, Wax drawing, Painting, Keep details painting, Color Coating, Prepare cleaning equipment, Remove wax resist and Cleaning cloth.

Aspects of this research were from the literature review. Statistical analysis was used to analyze rating numbered data from the questionnaire. These number data analyzed with Likert scales, which is a method to estimate the minimum to the maximum. Two different groups in this research were convenience or accidentally sampling. Participation in this study was anybody who was willing to be a part of this study in giving information. The first sample group was Batik painter from Suan Dusit University $(n=52)$. They were asked to do Batik with both paraffin wax and gel wax, start from Batik resist writing to Batik cleaning process. Then they were asked to compare their efficacy. The second sample group was consumers visiting the One Tambon One Product (OTOP) at Impact Arena Mueang Thong Thani $(n=103)$. All the participants were asked to evaluate Batik cloth made from paraffin wax and gel wax. (see Fig. 1)

\section{RESUlts}

The unique characteristics of gel wax resist material is in liquid form when it is in the pen-like instrument, and it becomes harder and solid when exposing to the air. It could be used with natural and synthetic fabric. The painting could be done right after drawing lines on the fabric with this gel wax resist material. The painter does not need to wait for drying of the resist material like the paraffin wax resist material. By comparison the two methods of batik making equipment revealed that, making batik with paraffin wax requires more equipment than another one processes; especially the gas stove for heating to melt the paraffin wax write on the textile and boiling water for dissolve the paraffin from the fabric. (see Fig. 2)

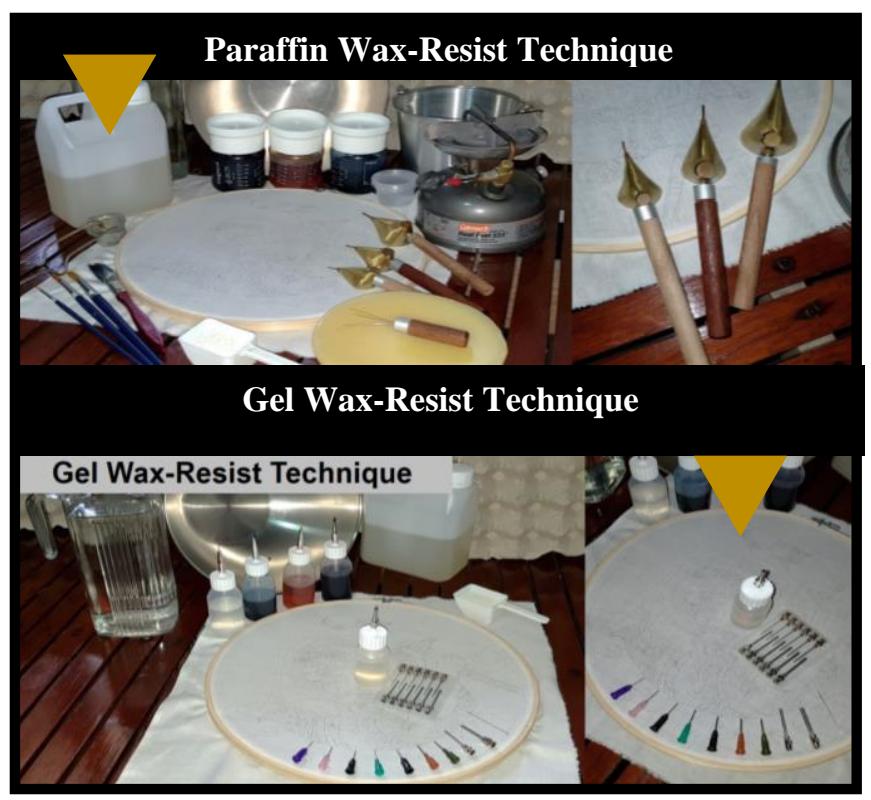

Fig. 2. Batik equipment. 
The result shows different satisfactions from paraffin wax resist material users in different aspects as follows. Users gave high satisfaction on the quality of the pen-like instrument, easiness of filling the resist material. The users gave medium satisfaction on the efficacy of resist material on bordering different dyes, the distinctness of the lines, consistency of the lines, easiness of direction control and draw, the size of pen-like instrument, no leak or drop of resist material from the instrument on the fabric, easiness of removing resist material from fabric, easiness of cleaning the pen tip. Regarding the odor of the resist material, the flow of material from the pen tip was lesser satisfaction and being able to change the size of the pen tip and safety from heat were the least satisfaction. (see Fig. 3 to Fig. 6)

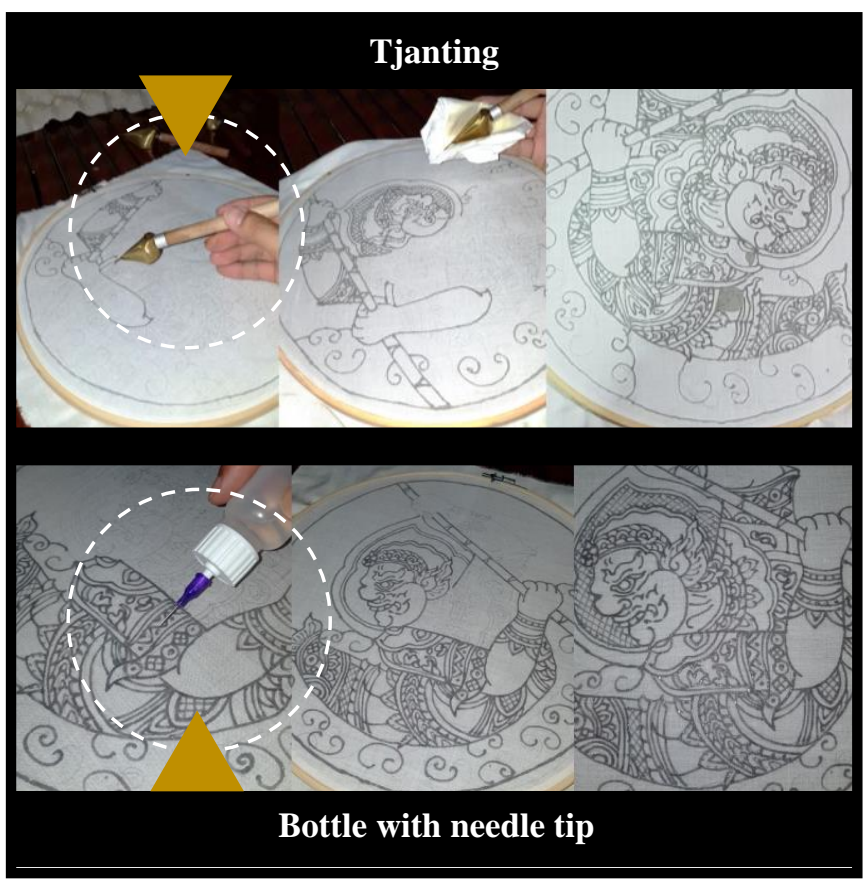

Fig. 3. Drawing process Paraffin (above) and Gel (below).

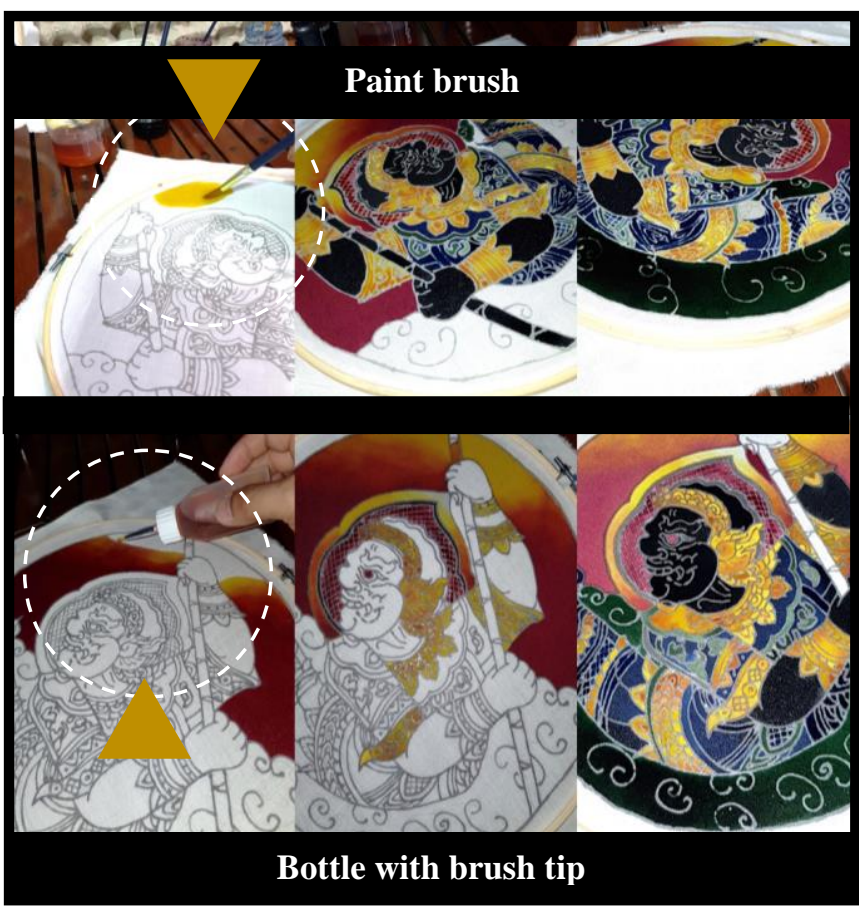

Fig. 4. Painting process Paraffin (above) and Gel (below).

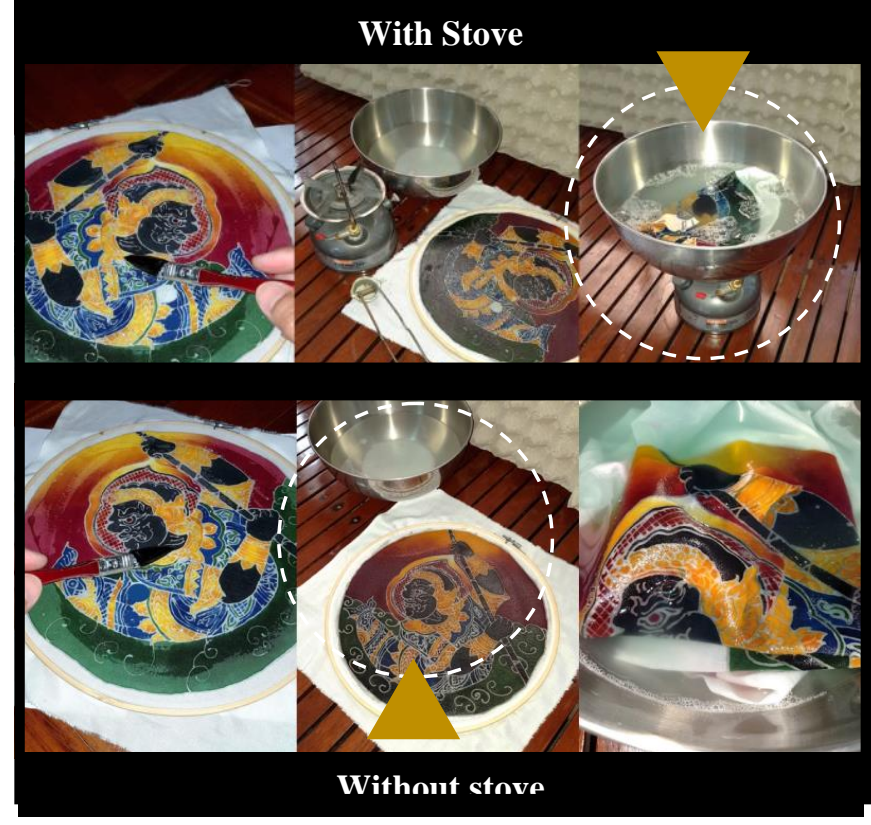

Fig. 5. Cleaning process Paraffin (above) and Gel (below).

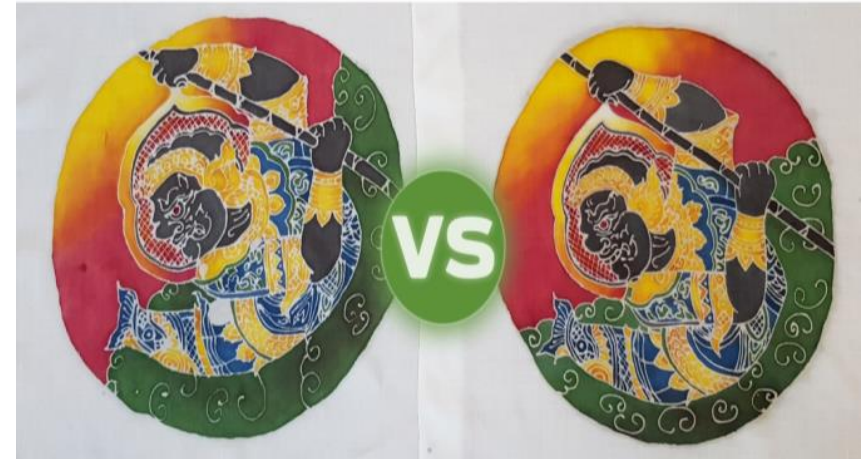

Fig. 6. Batik cloth Paraffin (left) and Gel (right).

The result shows different satisfactions from gel wax resist material users in different aspects as follows. Regarding being able to change the size of pen tips, safety from heat, and easiness of drawing was given the highest satisfaction. The aspects that were given the high satisfaction were resisted material could be a good border for different dyes, the distinctness of the lines, consistency of the lines, the size of pen tip, the quality of pen-like instrument, no leak or drop of resist material on the fabric, easiness of removing resist material from fabric, easiness of filling resist material and cleaning pen tip. Regarding no strong odor and the flow of material from the pen tip were given medium satisfaction. The result shows different satisfactions from gel wax resist material users (subjects) in different aspects as following. In terms of being able to change size of pen tips, safety from heat, and easiness of drawing were given the highest satisfaction. The aspects that were given the high satisfaction were resist material could be a good border for different dyes, the distinctness of the lines, consistency of the lines, the size of pen tip, the quality of pen-like instrument, no leak or drop of resist material on the fabric, easiness of removing resist material from fabric, easiness of filling resist material and cleaning pen tip. In terms of no strong odor and the flow of material from the pen tip were given medium satisfaction. (see Table I). 
TABLE I: EFFICACY COMPARISON BETWEEN PARAFFIN WAX AND GEL WAX AS RESIST MATERIALS

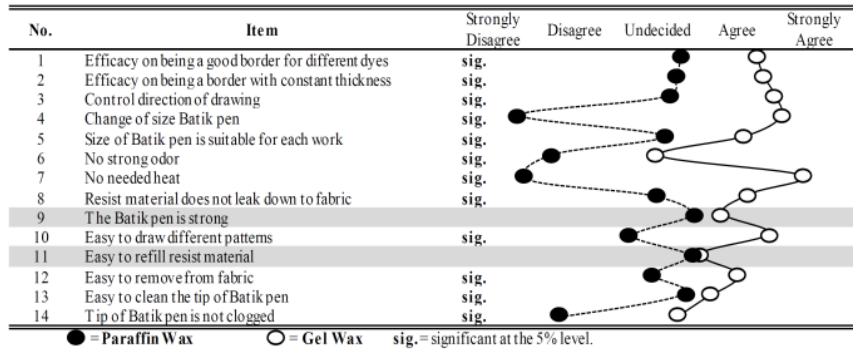

From Table I The results about efficacy of paraffin wax and gel wax resist material shows that these two materials are different in these following aspects - the distinctness of lines, the consistency of lines, the easiness of direction control, being able to change size of pen tips, the size for pen tip, odor, safety from heat, leaking or dropping of resist material from the instrument on the fabric, easiness of drawing, easiness of removing material from fabric, easiness of cleaning pen tip, and flow of material from pen tip. The means of the opinion on this efficacy from users using gel wax resist material were higher than the those of users using paraffin wax resist material with statistically significant $(p<0.05)$. Only two aspects - the quality of the instrument and the easiness of filling the material - were not significantly different $(p>0.05)$ Besides, the result regarded to traditional unique characteristics of Batik cloth made from paraffin wax resist material showed that the beautifulness and the uniqueness of Batik cloth were the highest. Regarding distinctness, smoothness, and detail of lines, brightness and shades of colors, cleanliness and neat of Batik cloth were high. While the traditional unique characteristics of Batik cloth made with gel wax resist material regarding beautifulness was the highest. The quality of Batik cloth made with both paraffin wax and gel wax resist materials were high regarding distinctness, smoothness, and detailed of lines, brightness and shades of colors, cleanliness and neat of the Batik cloth.

The comparison result of the unique characteristics of Batik cloth made from paraffin wax and gel wax showed that they were different in terms on the distinctness, smoothness, brightness, and detailed of lines, as well as cleanliness of Batik cloth. The results showed that the mean of those characteristics of Batik cloth made with gel wax resist material was statistically significantly higher than those of Batik cloth made with paraffin wax resist material $(\mathrm{p}<0.05)$. Only three aspects that both Batik cloth were not significantly different - shades of colors, neat and beautifulness of cloth $(\mathrm{p}>0.05)$. (see Table II)

TABLE II: COMPARISON OF BATIK TRADITIONAL UNIQUENESS BETWEEN PARAFFIN AND GEL TECHNIQUE

\begin{tabular}{|c|c|c|c|c|c|c|}
\hline No. & Item & $\begin{array}{l}\text { Sirongly } \\
\text { Disagree }\end{array}$ & Disagree & Undecided & Agree & $\begin{array}{c}\text { Sirongly } \\
\text { Agree }\end{array}$ \\
\hline 1 & Lines are distinct & sig. & & & & \\
\hline 2 & Lines are fragile and detailed & sig. & & & & \\
\hline 3 & Brightness of colors & sig. & & & 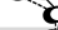 & \\
\hline 4 & Shades of colors & & & & & \\
\hline 5 & Neat of colors & sig. & & & & \\
\hline 6 & Cleanliness of cloth & sig. & & & के & \\
\hline 7 & Neat of cloth & & & & & \\
\hline 8 & Uniqueness of Batik & & & & & \\
\hline
\end{tabular}

A Comparison of time spent on Batik production between paraffin wax and gel wax resist material in Batik painting. The results showed that in the processes of the Equipment of the writing equipment preparing, Wax drawing, Prepare cleaning equipment and Cleaning Batik cloth. Making Batik with gel wax resist takes less time than making Batik with paraffin wax resist. On the other hand, Remove wax resist from the fabric. It can be seen that Batik with paraffin wax resist are less time used than Making Batik with gel wax. In conclusion, the total time of the Batik process with gel wax resist only takes 79.21 minutes but paraffin wax resist were 100.35 minutes (see Table III).

The important point is Batik with gel wax does not use heat to melt the resist material draw Batik pattern and squeeze the resist out from the fabric. It also reveals that the Batik with gel wax process uses only 7.28 liters of water while Batik with paraffin wax use 10.38 liters of water (see Table IV).

TABLE III: COMPARISON OF TIME USED IN BATIK PRODUCTION PROCESS BETWEEN PARAFFIN AND GEL WAX-RESIST

\begin{tabular}{lrr}
\hline \hline \multicolumn{1}{c}{ Batik process (Min.) } & gel wax & paraffin \\
\hline 1 Pen drawing & 5.39 & 4.82 \\
2 Equipment preparing & 5.17 & 16.35 \\
3 Wax drawing & 5.67 & 8.32 \\
4 Painting & 14.39 & 12.46 \\
5 Keep details painting & 7.96 & 9.64 \\
6 Color Coating & 3.21 & 3.28 \\
7 Prepare cleaning equipment & 7.39 & 16.96 \\
8 Remove wax resist & 15.57 & 6.71 \\
9 Cleaning cloth & 4.50 & 12.21 \\
\multicolumn{1}{c}{ Total time used } & $\mathbf{7 9 . 2 1}$ & $\mathbf{1 0 0 . 3 5}$ \\
\hline \hline
\end{tabular}

TABLE IV: COMPARISON OF WATER USED IN BATIK PRODUCTION PROCESS BETWEEN PARAFFIN AND GEL WAX-RESIST

\begin{tabular}{llr}
\hline \multicolumn{1}{c}{ Water use (Liters) } & gel wax & paraffin \\
\hline 1 Remove wax resist & 4.03 & 5.71 \\
2 Cleaning cloth & 3.25 & 4.67 \\
$\quad$ Total water used & 7.28 & 10.38 \\
\hline \hline
\end{tabular}

\section{CONCLUSION}

Gel wax resists material is suitable to use in Batik painting on all-natural fabric. It could lower expenses related to instrument, energy and process. Gel wax resists material is easy to remove from fabric with the use of detergent and without the need to boil. Gel wax resists material could substitute paraffin wax resist material in drawing lines and dots for Batik painting. However, gel wax resists material still has a few limitations because the characteristic of gel wax that is more elastic than paraffin wax. Therefore, gel wax resists material is more suitable for only drawing lines and being borders for different dyes. The pen-like instrument for containing gel wax resist material could be the change for different types between size 8 to 30 (total 23 sizes). This is the major reason that the lines made from gel wax resist material is different from paraffin wax resist material regarding the distinctness and smoothness of lines compared to paraffin wax resist material. Moreover, the sizes of pen tip that could be used with gel wax resist material are boarder than the sizes of paraffin wax resist material. Gel wax resists material could also be used with the pen with two tubes or three tube tips.

Overall of Batik making with gel wax resist material is more convenient, and the lines are good borders for different dyes, consistent, easy for direction control, able to change the size of pen tips, the size is suitable for the work and a new user, as well as easy to clean and remove from fabric. 
Moreover, the use of it could reduce the process, material and instrument in Batik making. Importantly, the Batik cloth made from gel wax resist material could conserve the special unique characteristics of Batik cloth compare to the traditional technique. This new technique also produces the smooth, detailed of lines as good as the traditional technique and better regarding producing distinct lines.

The Batik cost and Time spent on production process found that, the batik pen like instrument with the needle tips for gel wax technique are cheaper than Tjanting for Batik made from paraffin wax. Making Batik with gel wax do not need a heating device to melt the wax and boiling water to remove the wax resist from the fabric. As a result, it can reduce the cost of such devices. In terms of time spent in Batik production process with paraffin wax technique takes more time and more water than making Batik with gel wax 21.14 minutes and 3.10 liters respectively. Therefore, could said that Batik painting with gel wax resist material is more comfortable and more cost savings in the production process than the original Batik style.

\section{Suggestions}

The research is qualitative research which used systematically scientific equipment and data collection resulting in the qualitative responses that could be analyzed. The limitation of this study was the data collected from specific groups. Therefore, the result may be different from other group's responses. The researcher suggests that this data may apply only particular group.

Future research should do with different groups with different experiences in Batik painting. Such as the study should do with an expert in Batik expert and new Batik maker to compare their responses on the efficacy of gel wax resist material to get more information to improve or apply to Batik or related products in the future.

The researcher would like to suggest the future study to solve the limitations of gel wax resist material. 1) Gel wax could not make the crack like paraffin wax. 2) A strong odor of gel wax. All the improvement would help gel wax to be a good resist material work well like traditional paraffin wax and produce good quality of Batik cloth.

In terms of the physical limitations of soft gel wax resist. It is not possible to make a broken candle technique just like using a traditional paraffin wax resist. And still have a bad smell while working. In the next research, should study the development the Batik resist material to make a broken line pattern technique or color line just like using a traditional process. In order to preserve the culture of Batik painting continue to exist.

\section{ACKNOWLEDGMENT}

This research could not do without the support from Suan Dusit University, subjects in this study, all the questionnaire answers and all participants. The researcher would also like to thank the 2018 8th International Conference on Environment and BioScience (ICEBS 2018), Seoul, South Korea that give an opportunity to present this result which is one of the contributions of the research success.

\section{REFERENCES}

[1] K. Pinkul, Batik Painting Techniques, Bangkok, Kaofang Publishing Inc., 2002.

[2] W. Hongsuwan, Batik 2, Bangkok, Wadsilp Publishing Inc., 2002.

[3] N. Rojjanaudomsart, Batik Painting, Bangkok, Odeon Store Publishing Inc., 1993

[4] T. Thumthong, The Art of Batik Hand Painted Bangkok, Odeon Store Publishing Inc., 2002.

[5] S. Simsiri, Drawing Device Design for Polymer Hydrocarbon Gel Outlining Material in Batik Painting, Scholl of Graduate Studies, King Mongkut's Institute of Technology Ladkrabang, Thailand, 2006.

[6] M. Concha, Silk Painting for Beginner, Italy: Komenennve Vlagstesellschast mb. H, 2001.

[7] S. Srisawat, The Application of English Paper Craving Technique on Koh Kred Handcraft: A Case Stydy on Lampshade, 2003.

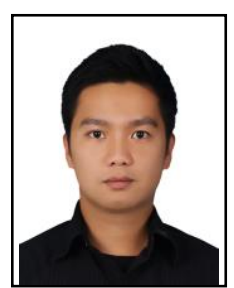

Sarath Simsiri is a lecturer, and product designer. He has a bachelor of science program in industrial product design, at the Faculty of Science and Technology, Rajabhat Institute Suan Dusit, Bangkok. He has a master of industrial education program in industrial design technology, at the Faculty of Industrial Education, King Mongkut's Institute of Technology Ladkrabang (KMITL), Bangkok and a doctor of architecture program in multidisciplinary design research, at the Faculty of Architecture from King Mongkut's Institute of Technology Ladkrabang (KMITL), Bangkok. Currently he is working as a lecturer in School of Tourism and Hospitality Management, Program in event and exhibition design, Suan Dusit University (SDU). Thailand. 